\title{
Reconstruction After Distal Gastrectomy for Gastric Cancer: Billroth 2 or Roux-En-Y Procedure?
}

\author{
EDOARDO VIRGILIO, GENOVEFFA BALDUCCI, PAOLO MERCANTINI, MARIO FERRI, TOMMASO \\ BOCCHETTI, SALVATORE CATERINO, PIER FEDERICO SALVI, VINCENZO ZIPARO and MARCO CAVALLINI \\ Medical and Surgical Sciences and Translational Medicine, \\ Faculty of Medicine and Psychology "Sapienza”, St. Andrea Hospital, Rome, Italy
}

\begin{abstract}
Background/Aim: Distal gastrectomy (DG) represents the only curative treatment for most mid-lower gastric cancers (GCs). As of 2017, however, no reconstructive modality to conduct after DG has gained unanimous consensus. Additionally, most authors have investigated Billroth 1 and Roux-en-Y (RY) rather than Billroth 2 (B2) reconstruction. We analyzed $B 2$ and $R Y$ gastrojejunostomy to identify the preferable technique and augment the available information on $B 2$ restoration. Patients and Methods: We retrospectively selected 132 GC patients who were consecutively submitted to DG at our institution between April 2005 and February 2016. B2 and RY anastomosis were accomplished as methods of reconstruction (respectively 36 and 96 cases). We compared these techniques in terms of clinicopathological, surgical, postoperative and oncologic outcomes. Results: Compared to RY gastrojejunostomy, B2 reconstruction was significantly associated with a greater mean number of harvested lymph nodes (26.03 vs. 21.65, $p=0.045$ ) but also with a longer hospital stay (22.8 vs. 15.7 days) $(p=0.022)$ and higher readmission rate $(28.57 \%$ vs. $3.1 \%$, $p<0.0001)$. On multivariate analysis, reconstruction method was the most significant independent prognostic factor for hospital readmission. Conclusion: In light of our results, we propose that B2 gastrojejunostomy deserves more study in order to better identify the best post-DG anastomosis.
\end{abstract}

Presently, despite significant advances in early diagnosis and postoperative management, gastric cancer (GC) remains the

Correspondence to: Prof. Edoardo Virgilio, Medical and Surgical Sciences and Translational Medicine, Faculty of Medicine and Psychology "Sapienza", St. Andrea Hospital, via di Grottarossa 103539, 00189, Rome, Italy. Tel: +39 0633775693, Fax: +39 0633775322, e-mail: aresedo1992@yahoo.it, edoardo.virgilio@uniroma1.it

Key Words: Billroth 2, Roux-en-Y, distal gastrectomy, gastric cancer. fifth most common malignancy and the third leading cause of cancer-related deaths worldwide (1). As of 2017, excluding some precociously selected cases (early GC, EGC), surgery represents the only possible curative treatment for most GCs including distal gastrectomy (DG) for middle-lower tumors (2). Billroth 1 (B1), Billroth 2 (B2) and Roux-en-Y (RY) are the reconstructive procedures of gastrointestinal tract continuity most frequently performed following DG throughout the world; to date, however, no technique has been considerably advocated more than others (3). In fact, although many authors have dealt with this subject in a profusion of works including randomized controlled trials, retrospective observational studies, metaanalyses and multi-institutional questionnaires, no approach resulted in clearly superior to others intra- and post-operative outcomes (1-26). Furthermore, the majority of the relative literature published in PubMed from 2010 through 2017 focused on B1 and RY, whether by open or laparoscopic surgery (in total 15 papers), rather than $\mathrm{B} 2$ reconstruction (5 articles comparing B1, B2 and RY among themselves, only 4 for B2 and RY and barely 2 entertaining the two Billroth procedures) (1, 2, 4-26). Hence it arises that more investigations on B2 anastomosis are needed in order to elucidate its advantages and downsides. To this intent, we herein present a retrospective analysis of DGs fashioned with B2 and RY procedures at our multi-surgical units' institution and offer a systematic literature review of the three leading reconstructions.

\section{Patients and Methods}

Study population. Between April 2005 and February 2016, 132 patients affected with middle or lower GC were consecutively submitted to elective DG at five different surgical departments (General Surgery Unit 1, 2, A, C and Emergency Surgery) of our Institution, St. Andrea's Hospital, Faculty of Medicine and Psychology, University of Sapienza, Rome, Italy. B2 and RY were the only adopted reconstruction methods. Medical records were obtained from the charts of each surgical division. Preoperative 
features, operative information and postoperative outcomes were investigated retrospectively (Table I). All histopathologic features were defined and analyzed in keeping with the American Joint Committee on Cancer (AJCC) staging system 7th edition, published in 2010 (27). Postoperative morbidity was assessed according to the Clavien-Dindo classification (28). Median follow-up time was 40.75 months (range $=2-130$ months): patients were surveilled by abdominal ultrasound, computed tomography, upper endoscopy and serum tumor markers.

Neoadjuvant/adjuvant therapy. A total of 4 patients (3\%) were given neoadjuvant chemotherapy. A total of 71 patients $(53.7 \%)$ received adjuvant therapy (chemo +/- radiotherapy). The regimen most frequently administered was ECF (epirubicin, cisplatin and 5fluorouracil).

Surgical techniques. Altogether, 16 different surgeons attending our institution performed all the cases of DG according to their own attitude. All DGs were made through open surgery and accomplished along with omentectomy, complete mesogastrium excision (29) and D1.5 lymph node dissection (that is perigastric lymphadenectomy extended to splenopancreatic nodes without performing splenopancreatectomy). Gastric lavage and peritoneal washing were performed before the manipulation of the tumor in all cases. All resected primary lesions and dissected lymph nodes were sent for definitive histological examination. Intraoperative esophagogastroscopy was performed in selected cases (when the tumor could not be macroscopically visualized and palpated using the fingers of both hands). Depending on early or advanced GC, the stomach was dissected by a linear stapling device respectively 3 and $5 \mathrm{~cm}$ proximally to the tumor site; the amount of stomach or the margin taken in DG made no difference in the type of reconstruction. In B2 reconstruction, a mechanical gastrojejunostomy was arranged with a linear stapler connecting part of the gastric remnant to the second jejunal loop (Finsterer's technique). Entering into surgical details, the resulting anastomosis involved the posterior wall of the gastric racket and was side-to-side, anisoperistaltic and infracolic (Figure 1a). A silicone drain was placed in the proximity of duodenal stump and gastrojejunostomy in all cases. In RY restoration, the jejunum was divided $20 \mathrm{~cm}$ distal to the ligament of Treitz. The jejunal loop (Roux limb) was brought up through the mesocolic route and gastrojejunostomy was confectioned by side-to-end isoperistaltic anastomosis (between cul de sac on the greater curvature side of the stomach and terminal margin of Roux limb) using a circular stapling device. In closing, the jejunal biliopancreatic limb was anastomosed to Roux limb $60 \mathrm{~cm}$ distal from the jejunal division: this anastomosis was end-to-side and hand-sewn in most cases, though some surgeons performed a side-to-side jejunojejunostomy with linear stapling device (Figure 1b). Two silicone drains were positioned in right and left subphrenic space in all cases.

Statistical analysis. Statistical analysis was performed using MedCalc for Windows, version 16.2.1 (MedCalc Statistical Software, Ostend, Belgium). All values are presented as means, standard deviation or numbers. Continuous variables were calculated using the Student's $t$-test or the Mann-Whithney $U$-test, whereas categorical variables were compared with the Pearson's chi-square test or the Fischer exact probability test. The one-way analysis of variance (one-way ANOVA) was used to determine any significant differences between the means of the two unrelated surgical techniques: all items showing significant variations were further analyzed using multiple regression analysis in order to eliminate confounding factors and assess their independency as prognostic factors. $p$-Values inferior to 0.05 were considered statistically significant.

\section{Results}

Preoperative features. After exclusion of GC patients submitted to total gastrectomy (67 cases) or palliative interventions, 132 patients submitted to elective DG were identified meeting the inclusion criteria. The clinicopathologic features of the study population is given in Table I. There were no significant differences in age, gender, comorbidity and neoadjuvant therapy between the B2 and RY group. Most patients $(60 \%)$ were in ASA class $3(17 \%$ B2 group vs. $87 \%$ RY group, $p=0.029)$. All interventions were conducted in elective setting.

Intraoperative, histological and cytopathological results. B2 and RY gastrojejunostomy were performed in $36(27.3 \%)$ and 96 cases $(72.7 \%)$ respectively. The choice of the type of reconstruction depended on several stochastic variables such as paternal surgeon's personal attitude, site of GC (middle or lower gastric position), size of remnant stomach and vascular variants; the stage of disease was not a criterion for deciding in favor of one modality of reconstruction. Altogether, four surgeons $(25 \%)$ performed at least one technique (at least one B2 and at least one RY), whereas eleven surgeons conducted only RY (68.75\%) and one surgeon executed only B2 $(6.25 \%)$. B2 reconstruction was significantly associated with a greater mean number of harvested lymph nodes (26.03 vs. 21.65, $p=0.045$ ) whereas the RY group had more cytopathological analyses (performed on gastric lavage and peritoneal washing) positive for cancer cells (9/41 vs. 1/21 case, $14.5 \%$ vs. $1.6 \%, p<0.0001)$. There were no differences in mean operative time (191 $\min v s .203 \mathrm{~min}, p=0.19)$ and mean estimated intraoperative blood loss $(186 \mathrm{ml} v s .157 \mathrm{ml}$, $p=0.24$ ) between B2 and RY procedure respectively. There were also similar results between the groups in the AJCC staging class, $\mathrm{T}$ depth, $\mathrm{N}$ status, mean number of positive nodes, mean LNR, Lauren's classification, lymphovascular invasion, perineural invasion, presence of signet ring cells and rates of curative resection. Most patients from both groups suffered from poorly differentiated GC (58.3\% for $\mathrm{B} 2,76.4 \%$ for RY group, $p=0.004)$.

Postoperative and oncological outcomes. Postoperative and oncological outcomes following B2 and RY procedures are shown in Table I. In comparison with RY, B2 reconstruction was significantly associated with a longer hospital stay (mean 22,8 days vs. 15,7 days) $(p=0.022)$ and higher readmission rate (10 vs. 3 cases, $27.7 \%$ vs. $3.1 \%, p<0.0001)$. There were no significant differences in terms of overall 
Table I. Clinicopathologic features of patients with B2 versus RY reconstruction after open DG for GC.

\begin{tabular}{|c|c|c|c|}
\hline & Billroth II $(\mathrm{n}=36)$ & Roux-en-Y (n=96) & $p$-Value \\
\hline \multicolumn{4}{|l|}{ Preoperative features } \\
\hline Mean age (yo) & $67\left(10^{\mathrm{a}}\right)$ & $68\left(13^{a}\right)$ & 0.732 \\
\hline Male gender & $19(52.7 \%)$ & $57(59.3 \%)$ & 0.496 \\
\hline ASA class $\geq 3$ & $6(16.6 \%)$ & $27(28 \%)$ & 0.029 \\
\hline Comorbidity & $12(35.2 \%)$ & $41(44.56 \%)$ & 0.353 \\
\hline Neoadjuvant therapy & 0 & $4(4.2 \%)$ & 0.270 \\
\hline \multicolumn{4}{|l|}{ Intraoperative, histologic and cytologic features } \\
\hline Tumor depth & & & 0.329 \\
\hline pT1 & $10(30.3 \%)$ & $26(28.57 \%)$ & \\
\hline pT2 & $7(21.21 \%)$ & $13(14.28 \%)$ & \\
\hline pT3 & $11(33.3 \%)$ & $27(29.67 \%)$ & \\
\hline pT4 & $5(15.15 \%)$ & $25(27.47 \%)$ & \\
\hline \multicolumn{4}{|l|}{ LN metastasis 0.952} \\
\hline pNO & $16(44.4 \%)$ & $43(44.8 \%)$ & \\
\hline $\mathrm{pN} 1$ & $7(19.4 \%)$ & $17(17.7 \%)$ & \\
\hline $\mathrm{pN} 2$ & $6(16.6 \%)$ & $17(17.7 \%)$ & \\
\hline $\mathrm{pN} 3$ & $7(19.4 \%)$ & $19(19.8 \%)$ & \\
\hline Mean number of harvested LNs & $26.3\left(14^{\mathrm{a}}\right)$ & $21.6\left(10^{\mathrm{a}}\right)$ & 0.045 \\
\hline Mean number of metastatic LNs & $4.9\left(8^{\mathrm{a}}\right)$ & $4\left(6^{\mathrm{a}}\right)$ & 0.534 \\
\hline Mean LNR & 0.216 & 0.173 & 0.379 \\
\hline \multicolumn{4}{|l|}{ AJCC stage 0.589} \\
\hline I & $16(44.4 \%)$ & $29(30.2 \%)$ & \\
\hline II & $8(22.2 \%)$ & $23(23.9 \%)$ & \\
\hline III & $9(25 \%)$ & $33(34.4 \%)$ & \\
\hline IV & $3(8.3 \%)$ & $11(11.4 \%)$ & \\
\hline Differentiation & & & 0.016 \\
\hline Well & $10(27.7 \%)$ & $6(6.74 \%)$ & \\
\hline Moderate & $4(11.1 \%)$ & $11(12.36 \%)$ & \\
\hline Poor & $21(58.3 \%)$ & $68(76.4 \%)$ & \\
\hline Undifferentiated & $1(2.7 \%)$ & $4(11.1 \%)$ & \\
\hline LVI & $16(44.4 \%)$ & $43(45.74 \%)$ & 0.894 \\
\hline PnI & $8(22.2 \%)$ & $15(16.3 \%)$ & 0.434 \\
\hline intestinal $v s .$. diffuse type & 14 vs. $10(58.3 \%)$ & 52 vs. $25(67.53 \%)$ & 0.410 \\
\hline signet ring cells & $9(25.7 \%)$ & $14(14.9 \%)$ & 0.155 \\
\hline $\mathrm{R} 1$ vs. R0 resection & $4(11.4 \%)$ & $9(9.6 \%)$ & 0.756 \\
\hline GL/PL cytology & $1(4.76 \%)$ & $9(21.95 \%)$ & $<0.0001$ \\
\hline Mean operative time $(\min )$ & $191\left(41^{a}\right)$ & $203(40 a)$ & 0.197 \\
\hline Mean estimated blood loss (ml) & $186\left(148^{\mathrm{a}}\right)$ & $157\left(116^{\mathrm{a}}\right)$ & 0.284 \\
\hline Surgeons acting only one technique & $1(6.25 \%)$ & $11(68.75 \%)$ & 0.0006 \\
\hline \multicolumn{4}{|l|}{ Postoperative and oncological features } \\
\hline Overall morbidity & $17(50 \%)$ & $31(32 \%)$ & 0.061 \\
\hline Clavien score $\geq 3$ & $10(28.57 \%)$ & $17(17.52 \%)$ & 0.166 \\
\hline Intestinal leak & $8(22.85 \%)$ & $13(13.68 \%)$ & 0.210 \\
\hline Reflux gastritis* & $3(8.3 \%)$ & $4(4 \%)$ & 0.284 \\
\hline Mean LOS (days) & $22.8(23 a)$ & $15.7(12 a)$ & 0.022 \\
\hline Mean postoperative LOS (days) & $16.6(23 a)$ & $13.6(11 a)$ & 0.108 \\
\hline Readmission & $10(28.57 \%)$ & $3(3.1 \%)$ & $<0.0001$ \\
\hline 90-day mortality & 0 & 0 & $\mathrm{NC}$ \\
\hline Mean time to metastasis/recurrence/GSC (mo) & $14.8\left(14^{\mathrm{a}}\right)$ & $29.2\left(30^{\mathrm{a}}\right)$ & 0.141 \\
\hline GSC & $4(11.76 \%)$ & $7(7.3 \%)$ & 0.434 \\
\hline Adjuvant therapy & $17(54.83 \%)$ & $54(56.84 \%)$ & 0.845 \\
\hline
\end{tabular}

Yo: Years, aStandard deviation; mo: months; min: minutes; LN: lymph node; LNR: lymph node ratio; LVI: lymphovascular invasion; PnI: perineural invasion; vs..: versus; R0: curative resection; R1: infiltrated margins; GL: gastric lavage with positive cytology; PL: peritoneal washing with positive cytology; ml: milliliters; LOS: length of stay; GSC: gastric stump carcinoma; NC: not classifiable, *shown on postoperative endoscopy plus biopsy. Significant $p$-values $(<0.05)$ are written in bold type. 


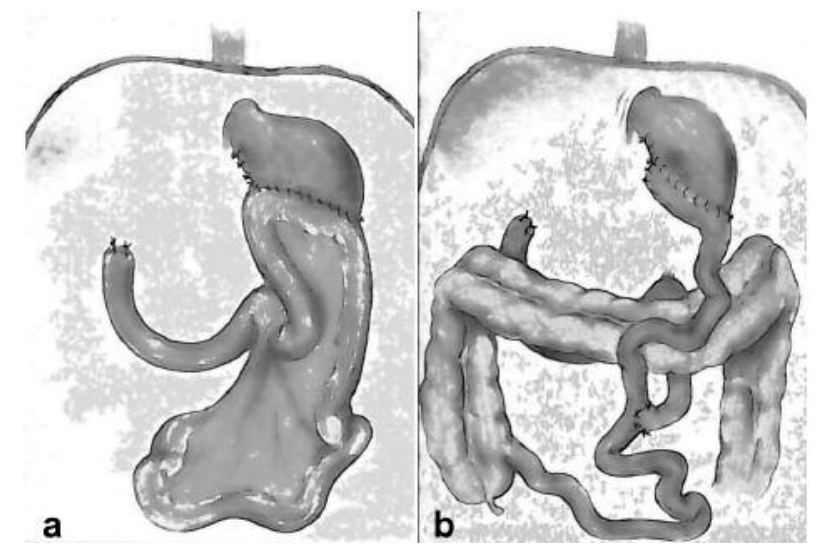

Figure 1. Types of reconstruction after distal gastrectomy: (a) Billroth 2 gastrojejunostomy (Finsterer's variant); (b) Roux-en-Y reconstructive method.

morbidity, major complication (Clavien grade $\geq 3$ ), anastomotic or intestinal leak, mean postoperative days, reflux gastritis, mean time to metastasis or recurrence (including gastric stump carcinoma), adjuvant chemoradiotheraphy. No death occurred at 30 and 90 days in any group $(0 \%, p$-value: not classifiable).

Prognostic analysis. The one-way ANOVA revealed that readmission rate showed significant differences between the two surgical techniques ( $p<0.001$, Table II, upper half). Such a result was upheld by multivariate analysis: in fact, reconstruction method was a significantly independent predictive factor for readmission $(p<0.0001$, Table II, lower half). Furthermore, to eliminate possible confounding factors, we verified if readmission rate was higher (or lower) with some surgeons or for advanced (versus initial) stages of disease. Multiple regression analysis showed no association of readmissions with these 2 variables ( $p=0.0006$ and $p=0.0037$ respectively, Table II, lower half). In this manner, the higher readmission rate for $\mathrm{B} 2$ in comparison with RY can be ultimately substantiated with certainty.

\section{Discussion}

Christian Albert Theodore Billroth reported the first successful partial gastrectomy for GC in 1881 (30). Since then, B1, B2 and RY became the three methods of gastrointestinal continuity restoration most studied and commonly practiced after DG for GC; currently, B1 and RY are the preponderant practice in East Asia, whereas RY and B2 techniques are more frequently undertaken in Western countries (16). As of 2017, however, the surgical community has not reached a full consensus concerning the preferable
Table II. Univariate (upper) and multivariate (lower) analysis of main outcomes in B2 vs. RY group.

\begin{tabular}{|c|c|c|c|c|c|}
\hline & \multicolumn{4}{|c|}{ Techniques } & \multirow[b]{2}{*}{$p$-Value } \\
\hline & B2* & SD & $\mathrm{RY}^{*}$ & SD & \\
\hline \multicolumn{6}{|l|}{ Outcome } \\
\hline Readmission & 0.28 & 0.45 & 0.03 & 0.17 & $<0.001$ \\
\hline Morbidity & 0.50 & 0.50 & 0.31 & 0.46 & NS $(0.061)$ \\
\hline GL/PL & 0.04 & 0.21 & 0.21 & 0.41 & NS (0.084) \\
\hline \multirow[t]{2}{*}{ Others } & & & & & $\mathrm{NS}(>0.1)$ \\
\hline & & \multicolumn{4}{|c|}{ Item: Readmission } \\
\hline \multicolumn{2}{|l|}{ Variables } & MRC & & SD & $p$-Value \\
\hline \multicolumn{2}{|c|}{ Type of reconstruction } & 0.53 & & 0.38 & $<0.0001$ \\
\hline \multicolumn{2}{|c|}{ Histological grade } & 0.25 & & 0.44 & 0.0037 \\
\hline \multicolumn{2}{|c|}{ Surgeons ${ }^{\circ}$} & 0.29 & & 0.42 & 0.0006 \\
\hline
\end{tabular}

*Mean values according to Scheffé test for comparisons, vs.: versus; SD: standard deviation; MRC: multiple correlation coefficient; GL: gastric lavage with positive cytology; PL: peritoneal lavage with positive cytology; NS: not significant $(p>0.05)$. ${ }^{\circ}$ To be intended as surgical parentage of each reconstructive act. Multiple regression analysis was performed only if the $p$-value of the outcome in the univariate analysis was $<0.05$. Significant $p$-values and corresponding outcomes/items are written in boldface.

technique to adopt (7). Such a longstanding indecision derives from the fact that each reconstruction is not exempt from disadvantages and limits and therefore no definite data can be concluded (31). Ours is the third study comparing B2 and RY reconstructions and the second from a Western country dealing with an open approach for this types of gastrojejunostomy $(16,17)$. Although many outcomes resulted to be similar between the two groups (no differences in mortality, Clavien score $\geq 3$, enteral leakage, postoperative reflux gastritis, mean time to recurrence/metastasis, development of GSC), we think that some of our results are clinically interesting and deserve discussion. Compared to RY, B2 reconstruction was significantly associated with a greater mean number of harvested lymph nodes (26.3 vs. 21.6 nodes, $p=0.045$ ). Indeed, such a feature can better assess both staging and prognosis for GC patients as suggested by the current AJCC (27). Actually, we do not know the explanation of this specific finding for a certainty. Such a parameter has been rarely investigated by the previous works dealing with these types of reconstructions and, furthermore, results were discordant and rarely significant $(16,17,19,20)$. Individual capabilities of surgeons can undoubtedly impact nodal harvest but more studies are needed in order to determine whether this phenomenon is fortuitous or peculiar to $\mathrm{B} 2$. On the other 
Table III. Review of the recent PubMed literature (2010-2017) on B1, B2 and RY reconstructions.

\begin{tabular}{|c|c|c|c|}
\hline References & Reconstructions & Nature of the study & Main statistical significant outcomes \\
\hline (1) & $\mathrm{oB} 1, \mathrm{oRY}$ & RCT questionnaire & $\begin{array}{c}\text { B1: lower weight loss }(0.046) \\
\text { RY: lower RG }(<0.001) \text { and } \mathrm{BR}(<0.001)\end{array}$ \\
\hline (2) & $\mathrm{oB} 1, \mathrm{oRY}$ & $\begin{array}{c}\text { Metanalysis of RCTs } \\
\text { and OCS }\end{array}$ & $\begin{array}{l}\text { B1: shorter OT (0.003) } \\
\text { RY: lower BR (0.001), RG (10-5), RE (0.02) }\end{array}$ \\
\hline (5) & $\mathrm{o} / 1 \mathrm{~B} 1, \mathrm{o} / 1 \mathrm{RY}$ & Multi-institutional questionnaire & NS for dumping syndrome \\
\hline (6) & o/l B1, o/l RY, & Multi-institutional questionnaire & $\begin{array}{l}\text { B1: lower weight loss }(0.022) \text {, } \\
\text { RY lower RE symptoms }(<0.0001)\end{array}$ \\
\hline (7) & oB1, oB2, oRY & Multi-institutional questionnaire institutions & RY stasis reported by $71 \%$ of the \\
\hline (8) & $\mathrm{oB} 1, \mathrm{oRY}$ & Retrospective questionnaire & $\begin{array}{l}\text { B1: higher RE }(0.0098) \\
\text { RY: lower RG }(0.0277)\end{array}$ \\
\hline (9) & $\mathrm{oB} 1, \mathrm{oRY}$ & Multi-institutional RCT & RY: lower RE (0.0037) and RG (0.0013) \\
\hline (10) & $1 \mathrm{~B} 1,1 \mathrm{RY}$ & Retrospective & B1: lower weight loss $(0.0002)$ \\
\hline (11) & $\mathrm{oB} 1, \mathrm{oRY}$ & Retrospective & RY: lower RG $(<0.05)$ \\
\hline (14) & $\mathrm{oB} 1, \mathrm{oRY}$ & Retrospective & RY: greater visceral fat loss $(0.0104)$ \\
\hline (16) & $\mathrm{oB} 2, \mathrm{oRY}$ & Retrospective & RY: longer OT (0.001), higher BL (0.033) \\
\hline (17) & 1B2, 1RY & Prospective & RY: longer LOS $(0.037)$ \\
\hline (18) & $\mathrm{oB} 1, \mathrm{oB} 2, \mathrm{oRY}$ & Retrospective questionnaire & NS \\
\hline (19) & 1B1, 1B2, IRY & Retrospective & $\begin{array}{c}\text { B1: shorter OT }(<0.001) \text { and LOS }(0.004) \\
\text { RY: lower RE and RG }(<0.001)\end{array}$ \\
\hline (20) & $1 \mathrm{~B} 1, \mathrm{BB} 2,1 \mathrm{RY}$ & Retrospective & NS for RE and RG \\
\hline (21) & oB1, oB2, oRY & Meta-analysis of RCTs & $\begin{array}{c}\text { B1: higher local recurrence }(<0.0001) \\
\text { B2: higher AL }(0.02) \\
\text { RY: lower RE and RG }(<0.0001)\end{array}$ \\
\hline (22) & $\mathrm{oB} 1, \mathrm{oB} 2, \mathrm{oRY}$ & Retrospective & NS for GSC \\
\hline (24) & $\mathrm{oB} 1, \mathrm{oB} 2$ & Meta-analysis & B2: amelioration of type 2 diabetes \\
\hline (25) & $1 \mathrm{~B} 2,1 \mathrm{RY}$ & Pro-retro-spective & B2: shorter length of operation $(0.001)$ \\
\hline (26) & $1 \mathrm{~B} 2,1 \mathrm{RY}$ & Retrospective & B2: shorter length of operation $(<0.010)$ \\
\hline (31) & lB1, $1 \mathrm{RY}$ & Retrospective & $\begin{array}{c}\text { B1: shorter OT }(0.017) \text {, less BL }(<0.0001) \\
\text { RY: higher RY stasis }(0.017) \text { longer LOS }(0.0039)\end{array}$ \\
\hline
\end{tabular}

O: Open surgery; 1: laparoscopy; RCT: randomized clinical trial; OCS: observational clinical studies; NS: not statistically significant; RE: reflux esophagitis; RG: remnant gastritis; BR: bile reflux; LOS: length of hospital stay; OT: mean operative time; BL: mean intraoperative blood loss; AL: anastomotic leakage; GSC: gastric stump carcinoma.

hand, counter to $\mathrm{B} 2, \mathrm{RY}$ procedure entailed a significantly shorter mean hospital stay (15.7 vs. 22.8 days, $p=0.022)$ and a lower readmission rate $(3.1 \%$ vs. $28.57 \%, p<0.0001)$. Of note, data on readmissions were further validated by univariate and multivariate analyses: in fact, the reconstructive method resulted to be a significantly independent predictive factor for this specific outcome $(p<0.001$ and $p<0.0001$ on uni- and multi-variate analysis respectively, entire Table II). To eliminate confounding factors, the multiple regression analysis was extended to the variables of histological grade and the 16 paternal surgeons acting the techniques (Table II, lower half): similarly to the type of surgical procedure, also these items were found to be significant independent prognostic and predictive factors for readmission (respectively $p=0.0037$ and $p=0.0006$ ). Differently from other works, in our study the mean length of stay described for both procedures was far longer (22 and 15 days respectively for $\mathrm{B} 2$ and $\mathrm{RY}$ in lieu of 7 to 9 days generally reported) $(16,17,19,20)$. This outcome is very likely to be related to the elevated mean age, severe comorbidities and high number of advanced stages of our patient population. The remaining clinicopathological features which showed statistical significance (such as ASA score and, in particular, cytological analysis of gastric lavage/peritoneal washing $) \quad(p=0.029$ and $<0.0006$, respectively) in this study, brought no clinical value but description differently from our previous works (32-35). Among the outcomes failing to reach statistical strength, overall morbidity had the lowest $p$-value $(p=0.061)$ pleading in favor of a better trend for RY over B2 (32\% vs. 50\%). Our data are in accordance with the world literature on B2 and RY reconstructions after DG for GC: just like that, we could not establish the preferable reconstructive procedure to perform $(1-30,36,37)$. In our case, this is probable due to the retrospective nature of our study and limited number of subjects. On the other hand, all the other papers hitherto 
published on B1, B2 and RY failed this object, although being prospective randomized works, meta-analyses, multiinstitutional observational studies or questionnaires $(1,2,4$ $31)$. We also made a systematic review of the literature on the three reconstructions published in PubMed from 2010 through 2017 and summarized it in Table III. B1 reconstruction is thought to provide three main advantages: technical simplicity with only one anastomosis, physiological route for food passing through the duodenum (that means natural regulation of gastrointestinal hormones with positive effect on digestion and absorption of food) and ease of postoperative endoscopy with access to the papilla of Vater $(1,2,4)$. On the other hand, as a consequence of the absence of the pyloric sphincter and a significantly larger angle of His, rapid gastric emptying, duodenogastric and gastroesophageal reflux can frequently occur; if chronic, the latter two conditions can lead to severe remnant gastritis up to GSC, lower esophagitis, Barrett's esophagus and cancer $(2,3,16)$. Moreover, some authors describe a higher fistula rate for gastroduodenostomy than gastrojejunostomy (B2 and $\mathrm{RY}$ ) due to excessive devascularization of duodenal stump and tension on the anastomosis $(2,3)$. Athwart B1, it is said that RY is the reconstruction having opposite advantages and disadvantages (8). Recently, due to some benefits such as prevention of bile reflux, alkaline gastritis and GSC, the frequency of RY reconstruction has been gradually increasing worldwide (8). On the other hand, RY necessitates a more articulate surgery with two anastomoses, meal runs an unphysiological course and postoperative endoscopic survey of the pancreatico-biliary system is improbable (8). Furthermore, three more problems have been associated with this reconstruction: stoma ulcer, Roux stasis syndrome and Petersen's internal hernia (8). The first complication occurs when the alkaline bile reflux into the stomach is reduced to zero and too much acid content impairs the vulnerable anastomosed mucosa of jejunum (36). The second occurs with Roux limb longer than $40 \mathrm{~cm}$ or when large section of the upper stomach left by the surgeon gets stuffed with food $(1,3,8)$. B2 reconstruction share some pros and cons belonging to B1 (not so demanding technique, feasibility of biliopancreatic investigation by postoperative endoscopy as well as greater incidence of duodenoenteric reflux into the gastric remnant with possible alkaline gastritis and stump cancer 15 to 20 years after surgery) as well as RY method (not physiological food passage, marginal ulcer, small gastric remnant or obese patients as preferable indications) $(17,22$, 23,37 ). Additionally, some advantages (amelioration of type 2 diabetes mellitus) and complications (such as afferent and efferent loop syndrome) accrue from B2 reconstruction only $(3,24)$. Compared to RY restoration, B2 entails shorter length of operation as demonstrated by our and other two recent dedicated works $(25,26)$. In this study, we found no significant differences in outcomes between the B2 and RY group: in our opinion, such a result could have been conditioned by some limitations lying in the structure of the search itself. First, the numerical discrepancy between the two examined populations (36 B2 versus 96 RY patients): a closer proximity could provide not only statistical power, but also a more reliable clinical significance. Second, the retrospective nature of our study could not exclude the fact that surgeons chose the right reconstruction for their individual patients. To obviate this encumbrance, our caveat is that double blind studies should be conducted for this type of comparison in the future. Third, a multi-institutional survey digging into larger amounts of patients could corroborate (or confute) our findings and come to more certain conclusions.

\section{Conclusion}

In light of our results, we propose B2 and RY two extremely cogent methods to adopt for gastrointestinal reconstruction after DG for GC. In particular, we think B2 deserves a more careful investigation of the one made today. Surgical studies dealing with fashions of gastrointestinal reconstruction after DG should not omit including this procedure in order to better assess advantages and encumbrances of each restorative technique and establish the preferable anastomotic practice.

\section{Conflicts of Interest}

The Authors declare no conflicts of interest.

\section{References}

1 Nakamura M, Nakamori M, Ojima T, Iwahashi M, Horiuchi T, Kobayashi Y, Yamade N, Shimada K, Oka M and Yamaue H: Randomized clinical trial comparing long-term quality of life for Billroth I versus Roux-en $\mathrm{Y}$ reconstruction after distal gastrectomy for gastric cancer. Br J Surg 103: 337-347, 2016.

2 Xiong JJ, Altaf K, Javed MA, Nunes QM, Huang W, Mai G, Tan CL, Mukherjee R, Sutton R, Hu WM and Liu XB: Roux-en-Y versus Billroth I reconstruction after distal gastrectomy for gastric cancer: a meta-analysis. World J Gastroenterol 19: 11241134, 2013.

3 Piessen G, Triboulet JP and Mariette C: Reconstruction after gastrectomy: which technique is best? J Visc Surg 147: 273-283, 2010 .

4 Imamura T, Komatsu S, Ichikawa D, Kosuga T, Okamoto K, Konishi H, Shiozaki A, Fujiwara H and Otsuji E: Reconstruction method as an independent risk factor for the postoperative decrease in hemoglobin in stage I gastric cancer. J Gastroenterol Hepatol 31: 959-964, 2016.

5 Tanizawa Y, Tanabe K, Kawahira H, Fujita J, Takiquchi N, Takahashi M, Ito Y, Mitsumori N, Namikawa T, Oshio A and Nakada K: Specific features of dumping syndrome after various types of gastrectomy as assessed by a newly developed integrated questionnaire, the PGSAS-45. Dig Surg 33: 94-103, 2016. 
6 Terashima M, Tanabe K, Yoshida M, Kawahira H, Inada T, Okabe H, Urushihara T, Kawashima Y, Fukushima N and Nakada K: Postgastrectomy syndrome assessment scale (PGSAS)-45 and changes in body weight are useful tools for evaluation of reconstreuction methods following distal gastrectomy. Ann Surg Oncol 21: S370-378, 2014.

7 Kumagai K, Shimizu K, Yokoyama N, Aida S, Arima S and Aikou T: Questionnaire survey regarding the current status and controversial issues concerning reconstruction after gastrectomy in Japan. Surg Today 42: 411-418, 2012.

8 Nomura E, Lee SW, Tokuhara T, Nitta T, Kawai M and Uchiyama K: Functional outcomes according to the size of the gastric remnant and the type of reconstruction following distal gastrectomy for gastric cancer: an investigation including total gastrectomy. Jpn J Clin Oncol 43: 1195-1202, 2013.

9 Hirao M, Takiguchi S, Imamura H, Yamamoto K, Kurokawa Y, Fujita J, Kobayashi K, Kimura Y, Mori M and Doki Y: Comparison of Billroth I and Roux-en-Y reconstruction after distal gastrectomy for gastric cancer: one-year postoperative effects assessed by a multi-institutional RCT. Ann Surg Oncol 20: 1591-1597, 2013.

10 Nomura E, Lee SW, Bouras G, Tokuhara T, Hayashi M, Hiramatsu M, Okuda J and Tanigawa N: Functional outcomes according to the size of the gastric remnant and the type of reconstruction following laparoscopic distal gastrectomy for gastric cancer. Gastric Cancer 14: 279-284, 2011.

11 Tanaka S, Matsuo K, Matsumoto H, Maki T, Nakano M, Sasaki $\mathrm{T}$ and Yamashita Y: Clinical outcomes of Roux-en-Y and Billroth I reconstruction after a distal gastrectomy for gastric cancer: what is the optimal reconstructive procedure? Hepatogastroenterology 58: 257-262, 2011.

12 Imamura H, Takiguchi S, Yamamoto K, Hirao M, Fujita J, Miyashiro I, Kurokawa Y, Fujiwara Y, Mori M and Doki Y: Morbidity and mortality results from a prospective andomized controlled trial comparing Billroth I and Roux-en_Y reconstructive procedures after distal gastrectomy for gastric cancer. World J Surg 36: 632-637, 2012.

13 Namikawa $T$, Kitagawa $H$, Okabayashi $T$, Sugimoto $T$, Kobayashi M and Hanazaki K: Roux-en-Y reconstruction is superior to billroth $\mathrm{I}$ reconstruction in reducing reflux esophagitis after distal gastrectomy: special relationship with the angle of his. World J Surg 34: 1022-1027, 2010.

14 Tanaka K, Takiguchi S, Miyashiro I, Hirao M, Yamamoto K, Imamura $\mathrm{H}$, Yano $\mathbf{M}$, Mori $\mathrm{M}$ and Doki $\mathrm{Y}$ : Impact of reconstruction method on visceral fat change after distal gastrectomy: results from a randomized controlled trial comparing Billroth I reconstruction and Roux-en-Y reconstruction. Surgery 155: 424-431, 2014.

15 Sasaki K, Miyachi K, Yoda N, Onodera S, Satomura H, Otsuka K, Nakajima M, Yamaguchi S, Sunagawa M and Kato H: Longterm comparison of boomerang-shaped jejunal interposition and Billroth-I reconstruction after distal gastrectomy. World J Surg 39: 1127-1133, 2015

16 Tran TB, Worhunsky DJ, Squires MH, Jin LX, Spolverato G, Votanopoulos KI, Cho CS, Weber SM, Schmidt C, Levine EA, Bloomston M, Fields RC, Pawlik TM, Maithel SK, Norton JA and Poultsides GA: To Roux or not to Roux: a comparison between Roux-en-Y and Billroth II reconstruction following partial gastrectomy for gastric cancer. Gastric Cancer 19: 994$1001,2016$.
17 Shim JH, Oh SI, Yoo HM, Jeon HM, Park CH and Song KY: Roux-en-Y gastrojejunostomy after totally laparoscopic distal gastrectomy: comparison with Billroth II reconstruction. Surg Laparosc Endosc Percutan Tech 24: 448-451, 2014.

18 Smolkas E, Lunevicius R and Samalavicius NE: Quality of life after subtotal gastrectomy for gastric cancer: does restoration method matter? - A retrospective cohort study. Ann Med Surg (Lond) 4: 371-375, 2015.

19 Kim CH, Song KY, Park CH, Seo YJ, Park SM and Kim JJ: A comparison of outcomes of three reconstruction methods after laparoscopic distal gastrectomy. J Gastric Cancer 15: 46-52, 2015.

20 Park JY and Kim YJ: Uncut Roux-en-Y reconstruction after laparoscopic distal gastrectomy can be a favorable method in terms of gastritis, bile reflux, and gastric residue. J Gastric Cancer 14: 229-237, 2014.

21 Zong L and Chen P: Billroth I vs. Billroth II vs. Roux-en-Y following distal gastrectomy: a meta-analysis based on 15 studies. Hepatogastroenterology 58: 1413-1424, 2011.

22 Morgagni P, Gardini A, Marrelli D, Vittimberga G, Marchet A, de Manzoni G, Di Cosmo MA, Rossi GM, Garcea D and Roviello F: Gastric stump carcinoma after distal subtotal gastrectomy for early gastric cancer: experience of 541 patients with long-term follow-up. Am J Surg 209: 1063-1068, 2015.

23 Takahasji M, Takeuchi H, Tsuwano S, Nakamura R, Takahashi T, Wada N, Kawakubo H, Saikawa Y and Kitagawa Y: Surgical resection of remnant gastric cancer following distal gastrectomy: a retrospective clinicopathological study. Ann Surg Oncol 23: 511-521, 2016.

24 Kwon Y, Jung Kim H, Lo Menzo E, Park S, Szomstein S and Rosenthal RJ: A systematic review and meta-analysis of the effect of Billroth reconstruction on type 2 diabetes: a new perspective on old surgical methods. Surg Obes Relat Dis 11: 1386-1395, 2015.

25 In Choi C, Baek DH, Lee SH, Hwang SH, Kim DH, Kim KH, Jeon TY and Kim DH: Comparison between Billroth-II with Braun and Roux-en-Y reconstruction after laparoscopic distal gastrectomy. J Gastrointest Surg 20: 1083-1090, 2016.

26 Cui LH, Son SY, Shin HJ, Byun C, Hur H, Han SU and Cho YK: Billroth II with Braun enteroenterostomy is a good alternative reconstruction to Roux-en-Y gastrojejunostomy in laparoscopic distal gastrectomy. Gastroenterol Res Pract 2017: 1803851, 2017.

27 Edge SB, Byrd DR, Compton CC, Fritz AG, Greene FL and Trotti A (eds): AJCC cancer staging manual (7th ed). New York, NY, Springer, 2010.

28 Clavien PA, Barkun J, de Oliveira ML, Vauthey JN, Dindo D, Schulick RD, de Santibañes E, E, Pekolj J, Slankamenac K, Bassi C, Graf R, Vonlanthen R, Padbury R, Cameron JL and Makuuchi $\mathrm{M}$ : The Clavien-Dindo classification of surgical complications: five-year experience. Ann Surg 250: 187-196, 2009.

29 Virgilio E, D'Antonio C and Balducci G: Mesogastrium recurrence as expression of the fifth metastatic route of gastric cancer. Med Hypotheses 82: 403-404, 2014.

30 Billroth T: Historical studies on the nature and treatment of gunshot wounds from the fifteenth century to the present time. Yale J Biol Med 4: 2-36, 1931.

31 Komatsu S, Ichikawa D, Kubota T, Okamoto K, Shiozaki A, Fujiwara H, Morimura R, Murayama Y, Kuriu Y, Ikoma H, Nakanishi M, Sakakura C and Otsuji E: Clinical outcomes and quality of life according to types of reconstruction following laparoscopy-assisted distal gastrectomy for gastric cancer. Surg Laparosc Endosc Percutan Tech 25: 69-73, 2015. 
32 Virgilio E, Giarnieri M, Montagnini M, D’Urso R, Proietti A, Mesiti A, Giovagnoli MR, Mercantini P, Cavallini M and Balducci G: Analyzing gastric lavage of gastric cancer patients: a prospective observational study on cytopathology and determination of intragastric CEA, CA 19.9, CA 72.4, and CA 50. Acta Cytol 60: 161-166, 2016.

33 Virgilio E, Giarnieri M, Montagnini M, D’Urso R, Proietti A, Mesiti A, Giovagnoli MR, Mercantini P, Cavallini M and Balducci G: Detection of cancer cells and tumor markers in gastric lavage of patients with gastric cancer: Do these findings have a clinicopathological significante and oncological implication? Med Hypotheses 94: 1-3, 2016.

34 Virgilio E, Proietti A, D’Urso R, Cardelli P, Giarnieri E, Montagnini M, Giovagnoli MR, Mercantini P, Balducci G and Cavallini M: Measuring intragstric tumor markers in gastric cancer patients: a systematic literature review on significance and reliability. Anticancer Res 37: 2817-2821, 2017.
35 Virgilio E, Giarnieri E, Giovagnoli MR, Montagnini M, Proietti A, D’Urso R, Mercantini P, Balducci G and Cavallini M: Early gastric cancer exfoliating into gastric lavage (GL1 EGC) shows a more aggressive behavior and poorer survival compared to the non-exfoliative counterpart (GL0 EGC). Anticancer Res 37: 4199-4203, 2017.

36 Hoya $\mathrm{Y}$, Mitsumori $\mathrm{N}$ and Yanaga $\mathrm{K}$ : The advantages and disadvantages of a Roux-en-Y reconstruction after a distal gastrectomy for gastric cancer. Surg Today 39: 647-651, 2009.

37 Park TY, Kang JS, Song TJ, Lee SS, Lee H, Choi JS, Kim HJ and Jang JW: Outcomes of ERCP in Billroth II gastrectomy patients. Gastrointest Endosc 83: 1193-1201, 2016.

Received August 21, 2017

Revised September 12, 2017 Accepted September 13, 2017 